\title{
SPECIAL DATA ACCORDING TO THE BRAIN-BASED LEARNING STRATEGY IN LEARNING SOME BASIC VOLLEYBALL SKILLS FOR FEMALE STUDENTS
}

\author{
Magda Hamid KAMBASH ${ }^{1}$ \\ Nidal Fadel ABBAS ${ }^{2}$ \\ Esraa Fadel ABBAS ${ }^{3}$
}

\section{Istanbul / Türkiye \\ p. 686-701}

Received: $15 / 11 / 2021$

Accepted: 04/12/2021

Published: 01/01/2022

This article has been scanned I iThenticat No plagiarism detected

\section{Abstract:}

The use of modern teaching strategies aims to develop the practices of female learners inside and outside the classroom, which contributes to changing the role of the student from a negative role to a positive role in general. Therefore, learning strategies have become involved in the application of many educational and teaching programs and curricula, as they greatly help in conveying information to the learner. With less effort and time, except that the material to be learned is theoretical or practical. In light of what the current era is witnessing of a huge knowledge explosion and a wide technological revolution that covered various areas of life, it has become necessary for researchers to be interested in searching for ways to ensure the development of thinking among learners, which is one of the foundations of correct learning, some strategies, means and methods used in the learning process help. To bring the learner to a stage where he can access knowledge on their own by applying that knowledge and using it to overcome the problems they face in their daily lives. He has to use different and multiple methods and methods, and this requires him to be familiar with how learning takes place, and how the teaching methods and means used affect the speed of achieving the goal of the learning process and the success of applying the educational curriculum and achieving its goals.

One of the features of the modern era is technological progress in various fields and situations of life, as rapid change has become a feature of the era in which we live. There is no doubt that its use affects all aspects of life, including education and teaching, and with this clear progress in the level of mastery of learning skills in sports events around the world, it has become necessary to use learning strategies in programs and curricula for

http://dx.doi.org/10.47832/2717-8293.15.47

1 ID) Prof. Dr. , Diyala University, Iraq, magda.hamid@uodiyala.edu.iq, http://orcid.org/0000-0002-4565-8856

2 (iD) Researcher, Diyala General Directorate of Education, Iraq, nedhalfadel@ gmail.com, http://orcid.org/0000-0001-9388$\underline{8755}$

3 (iD) Researcher, Diyala General Directorate of Education, Iraq, esraafaduil76@ gmail.com, http://orcid.org/0000-0003$\underline{1160-0135}$ 
teaching and teaching physical education and learning basic skills for all games and events Sports, including volleyball.

The researchers found the lack of use of modern strategies in the educational process, and despite their active role in learning basic skills using modern methods, it requires the presence of exercises that contribute to learning basic skills in volleyball, whose weakness emerged from the research sample, which casts a clear shadow on the performance and levels of learners. The aim of the research is to prepare special exercises According to the brain-based learning strategy in learning some basic volleyball skills for students of the second average, and to identify the effect of special exercises according to the brain-based learning strategy in learning some basic volleyball skills for students of the second average, and to identify the preference of the experimental and control groups in learning some basic volleyball skills for female students. The second is average. The researchers used the experimental approach for the experimental and control groups, and the research sample was represented by (30) students, then the sample was divided into an experimental group of (15) female students and a control group of (15) female students.

Key words: Special Exercises, Brain-Based Learning Strategy, Basic Skills. 


\section{أثر تمرينات خاصة وفقا لاستراتيجية التعلم المستند للدماغ في تعلم بعض المهارات الأساسية بالكرة الطائرة للطالبات}

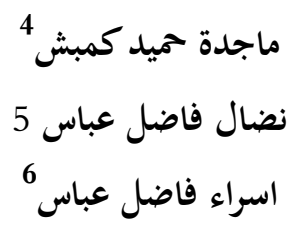

الملخص:

إن استخدام استراتيجيات التدريس الحديثة يهدف إلى تطوير ممارسات المتعلمات داخل الصف وخارجه مما يسهم في تغيير دور الطالبة من دور سلبي إلى دور إيجابي بشكل عام، لذلك أصبحت استراتيجيات التعلم تدخل في إنسات تطبيق الكثير من البرامج والمناهج التعليمية والتدريسية كوها تساعد بشكل كبير فئير في إيصال المعلومات إلى المتعلم بجهد ووقت أقل سوى كانت المادة المطلوب تعلمها مادة نظرية أو عملية. وفي ظل ما يشهره العصر الحالي من فئن تفجر معريف هائل وثورة تكنولوجية واسعة شملت بجالات الحياة المختلفة، بات من الضروري أن يهتم الباحثون في البحث عن السبل التي تكفل تنمية التفكير لدى المتعلمين والذي يعتبر إحدى أساسات التعلم الصحيح، تساعد بعض الاستراتيجيات والوسائل والطرق المستخدمة في عملية التعلم على إيصال المتعلم إلى مرحلة يستطيع فيها من

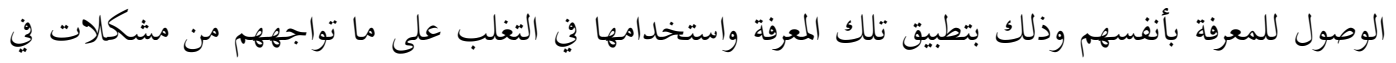

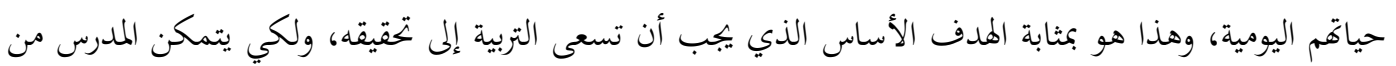

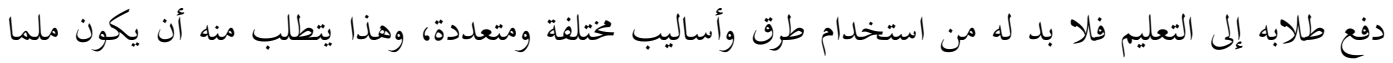
بكيفية حدوث التعلم، وكيف تؤثر الطرق والوسائل التدريسية المستخدمة فن سرعة تحقيق الهدف من عملية التعلم ونجاح تطبيق المنهج التعليمي وتحقيق أهدافه. الكلمات المفتاحية: تمرينات خاصة، استراتيجية التعلم المستند للدماغ، المهارات الأساسية.

إن من سمات العصر الحديث هو التقدم التكنولوجي في شتى بجالات ومواقف الحياة إذ أصبح التغير السريع هو سمة العصر الذي نعيش فيه، أن التطور التكنولوجي حقق طفرة كبير في علميات التعلم وما زال يخطو بخطوات ثابتة لتحقيق المزيد من التطور

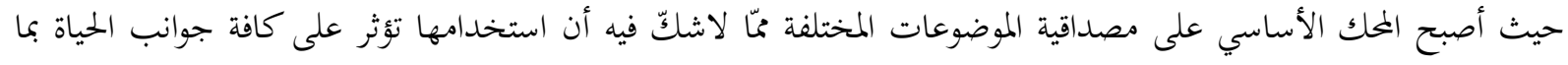
فيها التعليم والتدريس، ومع هذا التقدم الواضح في مستوى اتقان تعلم المهارات في الفعاليات الرياضية على مستوى العالم أصبح من الضروري استخدام استراتيجيات التعلم في برامج ومناهج تعليم وتدريس مادة التربية الرياضية وتعلم المهارات الأساسية لكافة الألعاب والفعاليات الرياضية ومنها لعبة الكرة الطائرة. 
تبين للباحثون قلة استخدام الاستراتيجيات الحميثة في العملية التعليمية ورغم دورها الفاعل في تعلم المهارات الأساسية

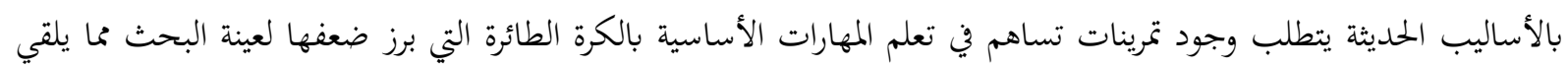
بظلالة بشكل واضح على اداء المتعلمين ومستوياقم.وهدف البحث إلى اعداد تمرينات خاصة وفقاً لاستراتيجية التعلم المستند

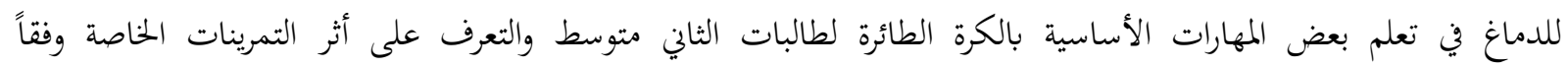

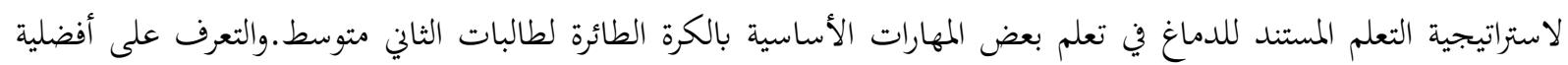
المجموعتين التجريبة والضابطة في تعلم بعض المهارات الأساسية بالكرة الطائرة لطالبات الثاني متوسط. واستخدم الباحثون المنهج

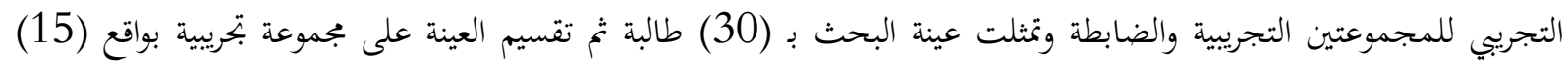
طالبة وبجموعة ضابطة بواقع (15) طالبة، وتمثل مجتمع البحث بطالبات الصف الثاني متوسط في القارعة للبنات في محافظة ديالى،

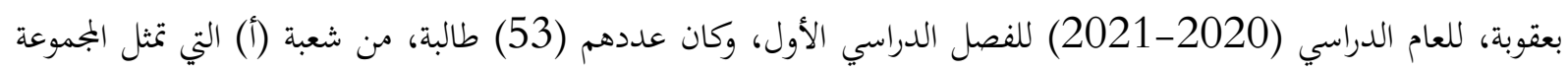

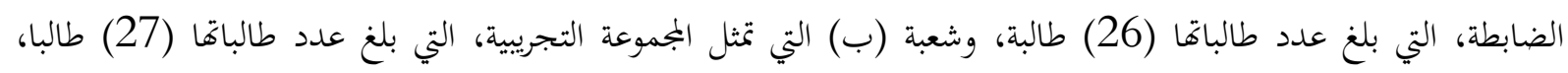
اختارت الباحثون عينة البحث بطريقة عشوائية عن طريق (القرعة)، فبلغ عدد افراد العينة (30) طالبة، موزعين بواقع (15) (15) طالبة البه

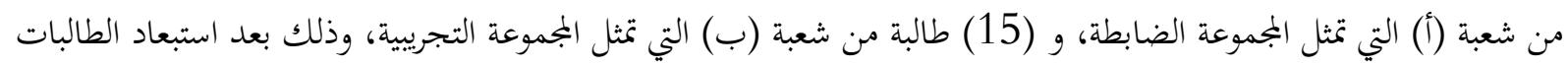

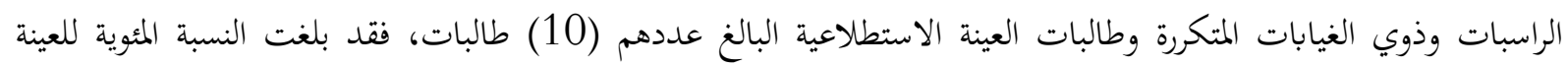

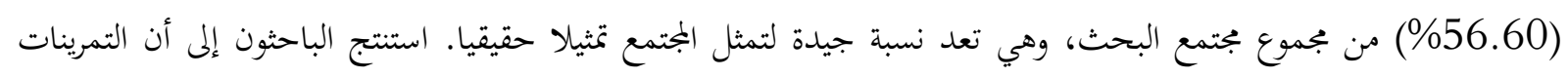

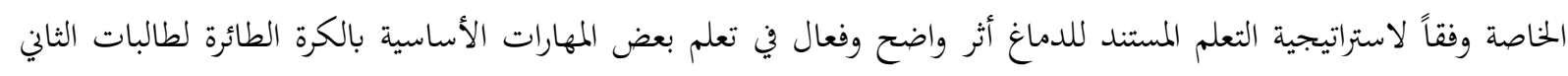

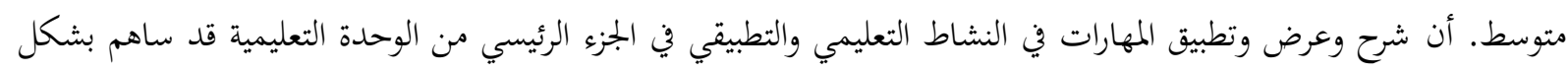

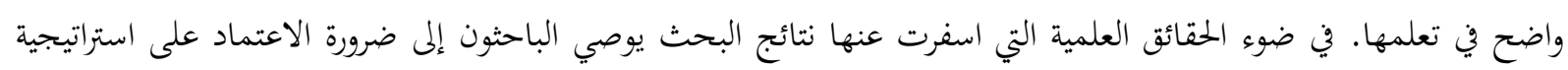

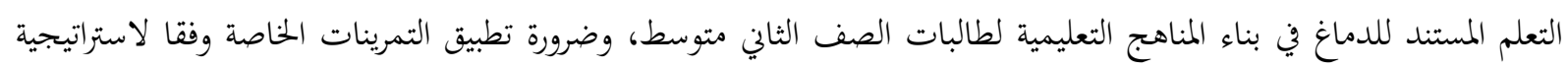

$$
\text { التعلم المستند للدماغ على عينات أخرى. }
$$

\section{1}

إن العملية التعليمية تركز على وسيلة مهمة، وهي نقل المعارف، والمعلومات من المدرس إلى الطالب، وبالطريقة المناسبة، وهذا يأتي عن طريق اختيار أفضل الطرائق، والنماذج، والاستراتيجيات التي تلائم المرحلة العمرية للمتعلّمين، ومنها استراتيجية التعلم

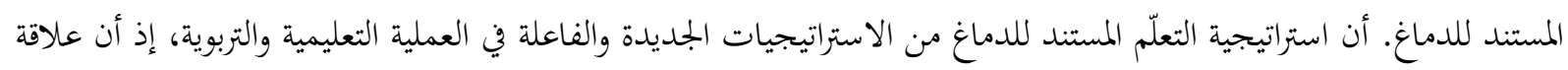

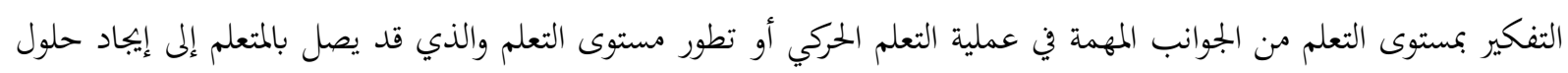

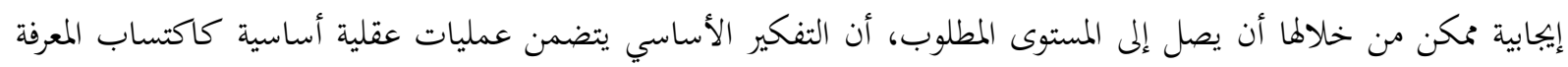

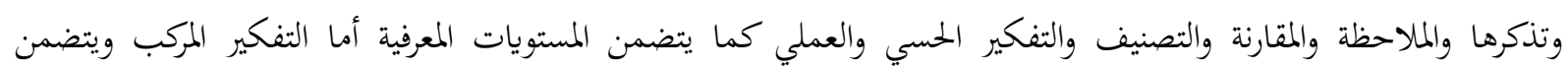

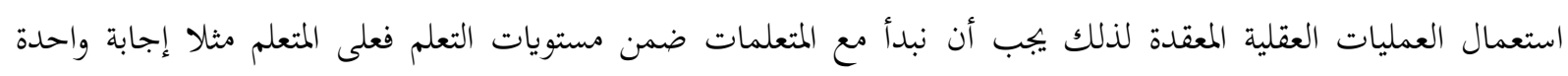

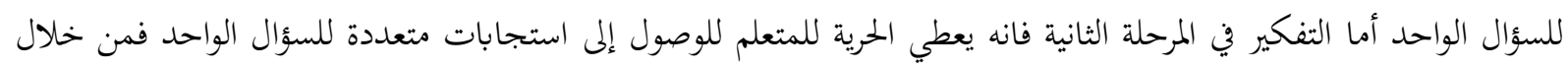

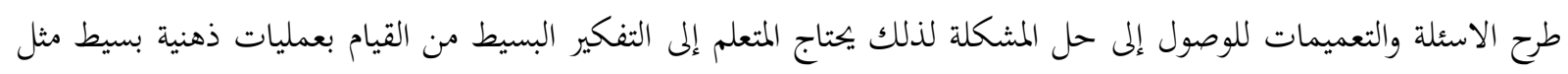
التذكر والاسترجاع والعودة إلى عملية الربط بين الجانب النظري والجانب التطبيقي لتعلم اي مهارة مثلا وهذا يتطلب التبات المرور

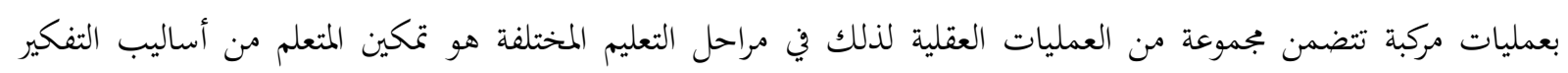

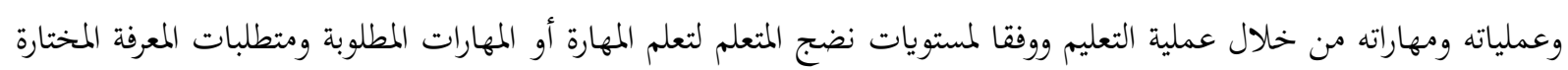
ووفقا لخصائص وبيئة التعلم التي يدور فيها التعليم وفي ضوء العلاقات التهات المتبادلة بين المعلم والمتعلم. 
إِنَّ لكُكّ لعبة من الألعاب الرياضية مهارات أساسية خاصة بها، فالكُة الطائرة إحدى الألعاب الرياضية التي انتشرت على

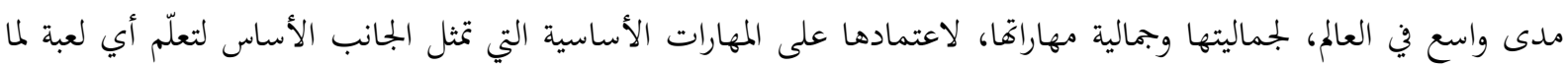

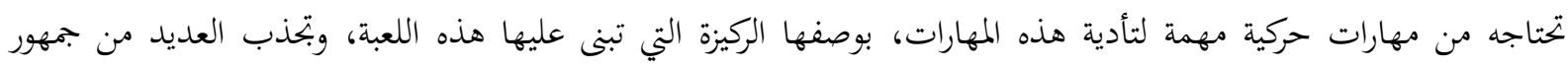

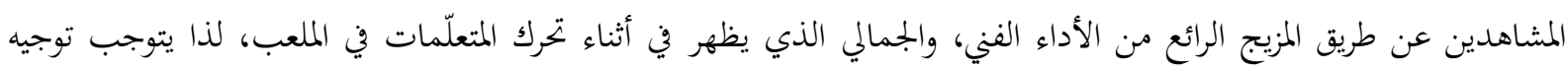

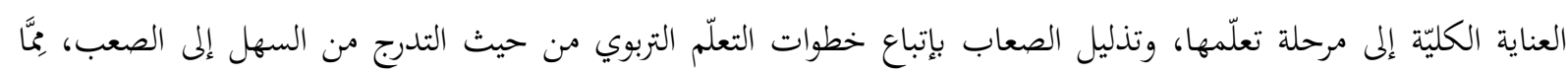
يجعلها أكثر أثارة، وتشويقًا وتنافسًا بالاعتماد على أسس علمية صحيحة تساعد على سرعة التعلّم، ومن هنا تبرز أهمية البحث في في إلى تَعَرُْف تأثير استراتيجية التعلم المسند إلى الدماغ، وذلك لتناغمها وفاعليتها للتطبيقات التي تعنى في مجال الفروق الفردية بين

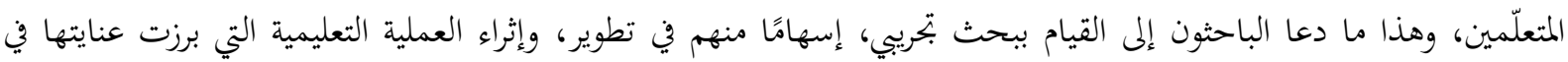

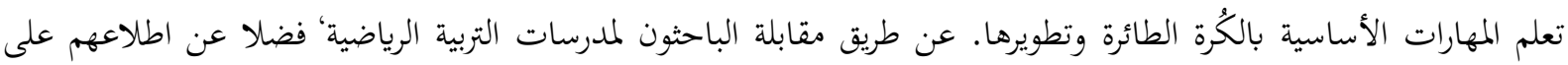
مجموعة من الدراسات والمصادر المتعلقة بالموضوع، تبين للباحثون قلة استخدام الاستراتيجيات الحديثة في العملية التعليمية ورغم دورها الفاعل في تعلم بعض المهارات الأساسية بالأساليب الحديثة مما يتطلب وجود تمرينات خاصة تساهم في تعلم المهارات

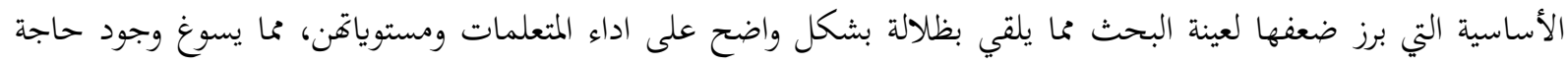

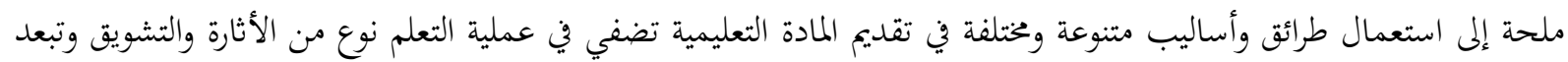
الملل عن الدرس وتسهم بشكل إيجابي في مشاركة الطالبات في عرض المهارة، ولذلك ارتى الباحثون القيام مهذه التجربة من خلال استخدام التمرينات الخاصة وفقا لاستراتيجية التعلم المستند للدماغ في تعلم بعض المهارات الأساسية بالكرة الطائرة للطالبات وهدف البحث إلى اعداد تمرينات خاصة وفقا لاستراتيجية التعلم المستند للدماغ في تعلم بعض المهارات الأساسية بالكرة الطائرة

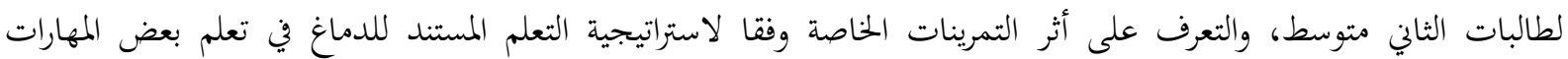
الأساسية بالكرة الطائرة لطالبات الثاني متوسط، والتعرف على أفضلية المجموعتين التجريبية والضابطة في تعلم بعض المهارات

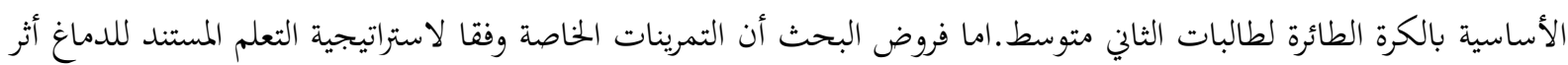
في تعلم بعض المهارات الأساسية بالكرة الطائرة لطالبات الثاني متوسط، وهنالك أفضلية للتمرينات الخاصة وفقا لاستراتيجية التعلم المستند للدماغ عن الأسلوب المتبع في تعلم بعض المهارات الأساسية بالكرة الطائرة لطالبات الثاني متوسط.

البجال البشري: طالبات الصف الثاني متوسط في متوسطة القارعة للبنات (للعام الدراسي 2020-2021)

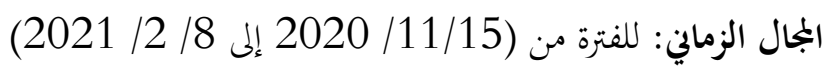
الجمال المكاني: ساحة متوسطة القارعة للبنات

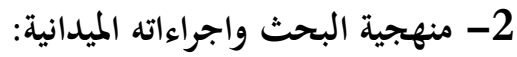

إن اختيار المنهج الملائم لمشكلة البحث وأهدافه من المتطلبات الضرورية في البحث العلمي، إذ استخدم الباحثون المنهج

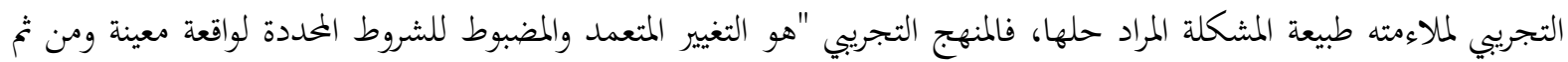

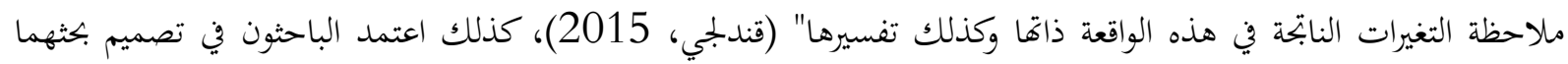
على أسلوب المجموعتين المتكافئتين (التجريبية والضابطة). 


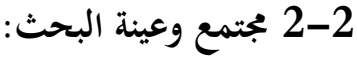

تم تحديد بجتمع البحث طالبات الصف الثاني المتوسط في متوسطة القارعة للبنات، للعام الدراسي (2020-2021) للفصل الدراسي الأول، وكان عددهم (53) طالبة، من شعبة (أ) التي تمثل المجموعة الضابطة، التي بلغ عدد الطالبات (26)

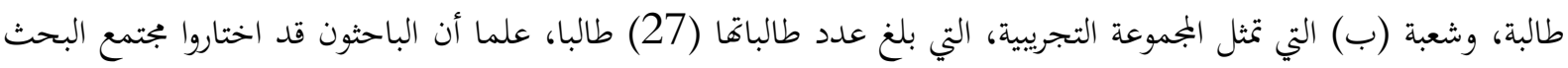

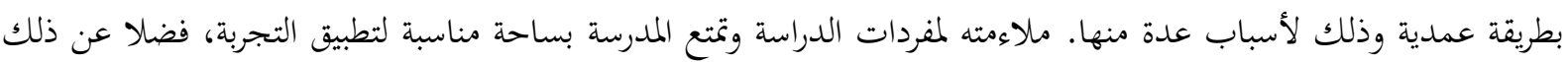

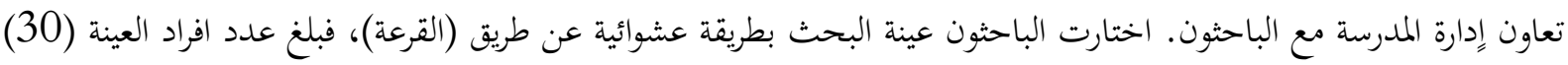
طالبة، موزعين بواقع (15) طالبة من شعبة (أ) التي تمثل المجموعة الضابطة، و (15) طالبة من شعبة (ب) التي تمثل المجموعة التجريبة، وذلك بعد استبعاد الطالبات الراسبات وذوي الغيابات المتكررة وطالبات العينة الاستطلاعية البالغ عددهم (10) طالبات.درس الباحثون طالبات المجموعة التجريبية على وفق استراتيجية التعلم المستند للدماغ، بينما درست المجموعة الضابطة

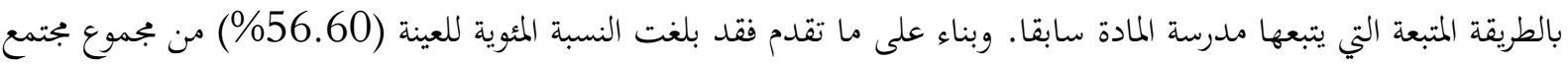
البحث، وهي تعد نسبة جيدة لتمثل المجتمع تمثيلا حقيقياً

الجدول (1) يبين بتحانس عينة البحث في متغيرات (العمر، والطول، والكتلة)

\begin{tabular}{|c|c|c|c|c|c|c|}
\hline معامل الالتو اء & الوسيط & الالانحرياري & الحسابي & وحدة القياس & المتغير ات & $ت$ \\
\hline 1.05 & 14.00 & 1.31 & 14.46 & سنة & العمر & 1 \\
\hline $0.50-$ & 158.00 & 2.47 & 158.41 & سم & الطول & 2 \\
\hline $0.68-$ & 46.00 & 3.48 & 46.56 & كغ & الكتلة & 3 \\
\hline
\end{tabular}

قيم معامل الالتواء محصورة ما بين 3د3، وهذا يدلّ على أن الدرجات موزعة توزيعًا اعتداليًا.

2-2 3 وسائل جمع المعلومات والادوات والأجهزة المستخدمة في البحث:

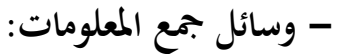
المصادر العربيّة والأجنبية، استبانة تحديد اهم الاختبارات المستخدمة بالبحث، فريق العمل المساعد' الملاحظة العلمية، المعالجات الاحصائية.

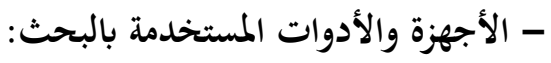
استخدم الباحثون الأدوات الآتية: ملعب كرة طائرة قانوين مع مستلزماته عدد (1)، كرات طائرة نوع (Mikasa) صينية الصنع، عدد (15) (15) كرة، ميزان

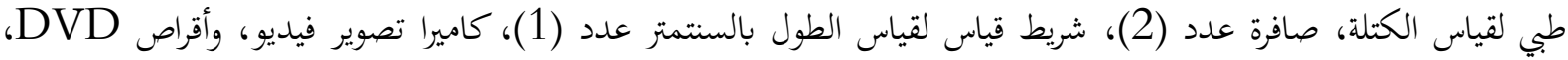
جهاز كومبيوتر نوع Lenovo عدد (1)، ساعة توقيت عدد (1).

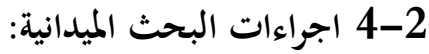

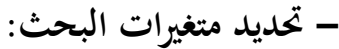

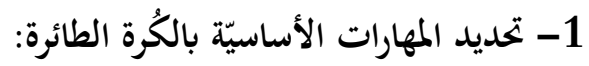
عن طريق المنهج المعتمد لوزارة التربية للمرحلة المتوسطة (الصف الأول متوسط) بالكُرة الطائرة (اخرون، 2012)، تم تحديد المهارات الأساسيّة (قيد البحث)، وهي: الإرسال المواجه من الأسفل، التمرير من الأعلى، التمرير من الأسفل) . 
قام الباحثون بإعداد استمارة لتحديد أهم الاختبارات التي تقيس الأداء المهارى للمهارات قيد البحث، وتم عرض تلك

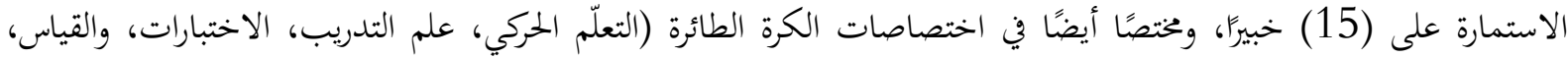

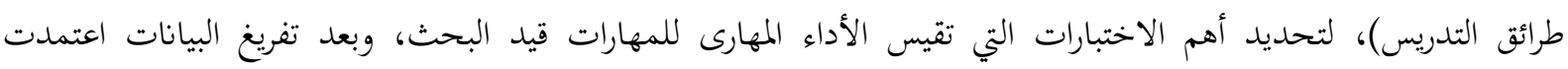

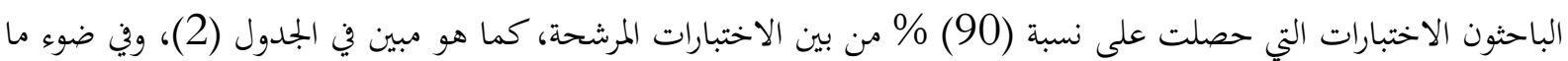
أفرزته استمارة الاستبانة، تم تحديد الاختبارات المهارية قيد البحث. الجلدول (2) يبيّن النسب المئوية للاختبارات المرشحة لقياس الأداء المهاري للمهارات قيد البحث

\begin{tabular}{|c|c|c|c|c|}
\hline المئو النسبة & الغرض من الاختبار & الاختبار ات المرشحة & 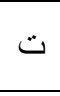 & 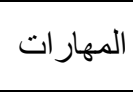 \\
\hline$\% 91$ & قالخبر اء. مستوى الأداء المهاري للإرسال عن طريق & إرسال إلى الجهة الأخرى من الملعب & 1 & \multirow{3}{*}{ الإلمو اجسه } \\
\hline$\% 65$ & قوقف مشابه للإِبار اة. لدى لاعب الكُرة الطائرة في & 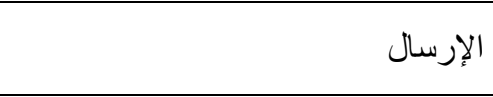 & 2 & \\
\hline$\% 68$ & 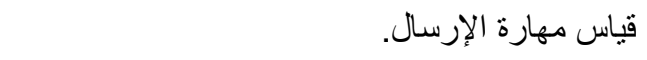 & 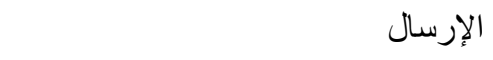 & 3 & \\
\hline$\% 86$ & قياس مستوى الأداء المهاري عن طريق الخبر اء. & المناولة فوق الر أس مستمرّة من الأعلى & 1 & \multirow{3}{*}{ الأنمرير } \\
\hline$\% 64$ & قن مهارة قدرة المختبر من أعلى برعة الأصابع. & اختبار تكرار التمرير على الحائط & 2 & \\
\hline$\% 66$ & قياس دقة التمرير من أعلى. & دقة التمرير على الحائط & 3 & \\
\hline$\% 88$ & قياس مستوى الأداء المهاري عن طريق الخبر اء. & التمرير من الأسفل & 1 & \multirow{3}{*}{ 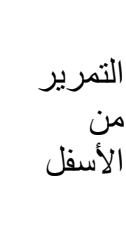 } \\
\hline$\% 60$ & تمكنه من مهارة التمرير من سن أسفل باليدين. ومقدار & اختبار التمرير من أسفل بالذراعين & 2 & \\
\hline$\% 69$ & قياس دقة التمرير من أسفل. & دقة التمرير على الحائط & 3 & \\
\hline
\end{tabular}

3- الاختبارات المهارية للمهارات الأساسيّة قيد البحث:

- الاختبار الأول : إرسال إلى الجهة الأخرى من الملعب (الشيخلي، 2016).

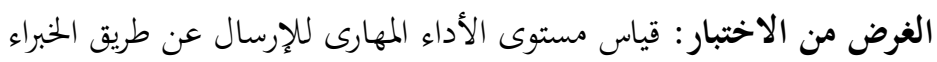

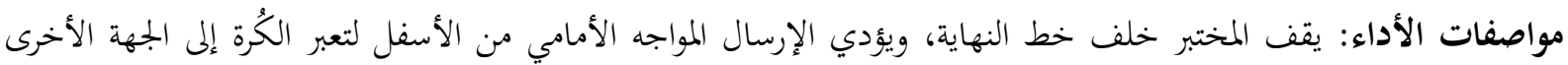
من الملعب، إذ يعطى لكُّل مختبر ثلاث محاولات. التسجيل: يتم تقييم أداء المختبر في المحاولات الثلاث عن طريق الخبراء، ويكون تقسيم الدرجة على النحو الاتي: (الجزء التحضيري: ودرجته (3)، الجزء الرئيس: ودرجته (5)، الجزء الختامي: ودرجته (2) )

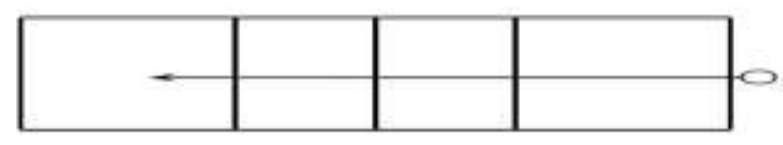

الشكل (1) اختبار الإرسال إلى الجهة الأخرى من الملعب

- الاختبار الثاني: المناولة فوق الرأس مستمرّة من الأعلى (الشيخلي، 2016) الغرض من الاختبار: قياس مستوى الأداء المهاري عن طريق الحبراء. مواصفات الأداء: يؤدي المختبر مناولة فوق الراس مرّة بعد مرّة (سيطرة على الكُرة)، ويعطى للكُّ مختبر ثلاث محاولات. 
التسجيل: يتم تقييم أداء المختبر في المحاولات الثلاث عن طريق الخبراء، ويكون تقسيم الدرجة كالآتي: (الجزء التحضيري: ودرجته

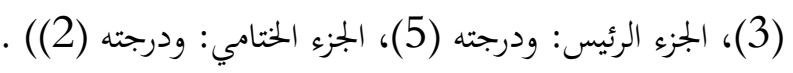

- الاختبار الثالث: التمرير من الأسفل: (الشيخلي، 2016) الغرض من الاختبار: قياس مستوى الأداء المهاري عن طريق

مواصفات الأداء: يؤدي المختبر مناولة من الأسفل مرّة بعد مرّة (سيطرة على الكُرة)، ويعطى لكُلّ مختبر ثلاث محاولات.

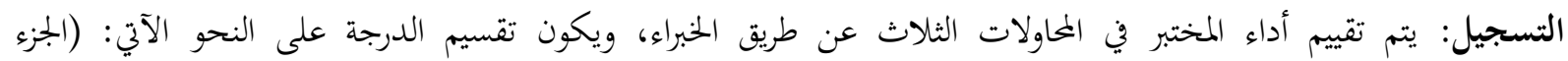
التحضيري: ودرجته (3)، الجزء الرئيس: ودرجته (5)، الجزء الختامي: ودرجته (2))

4- 4 التجربة الاستطلاعية:

التجربة الاستطلاعية هي: "تحربة صغيرة، أو عمل مصغر للدراسة العامة يقوم بها الباحث بغية الوقوف على السلبيات والإيجابيات التي ترافق إجراء التجربة الرئيسة للبحث" (صالح، 2004)، ومن أجل التأكد من سلامة الإجراءات، والطريقة التي لئي

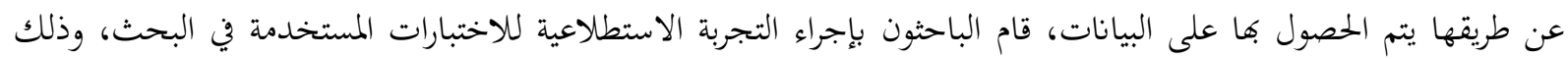

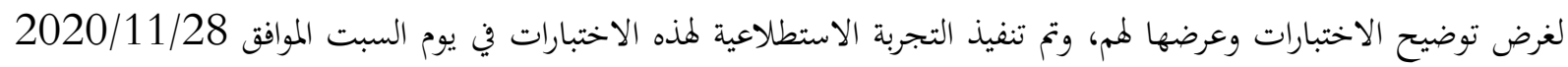
في تمام الساعة التاسعة صباحًا، والهدف منها: تَعَرُف الصعوبات والمعوقات التي قد توراجه الباحثون في أثناء تطبيق الاختبارات

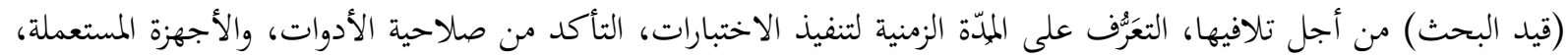

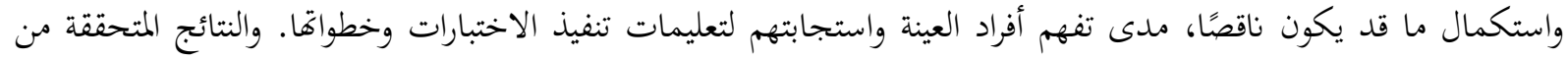
التجربة الاستطلاعية: (صلاحية الأدوات والأجهزة المستخدمة صلاحية الاختبارات المستخدمة جميعها من حيث تمتعها بالوقت المناسب للتنفيذ، وصلاحية المكان، وسهولة تطبيق عينة البحث للاختبارات، تفهم فريق العمل المساعد في طريقة تنفيذهم لاختبارات البحث).

\section{5- 5 الأسس العلمية للاختبارات المستخدمة في البحث:}

إنَّ من أهم خصائص الاختبار أو القياس الجيد هو توافر معاملات الصدق، والثبات، والموضوعية، فيتم ذلك عند

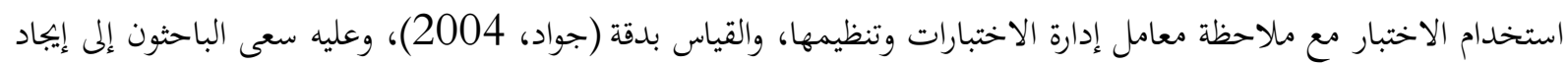
الأسس العلمية للاختبارات المختارة على النحو الآتي:

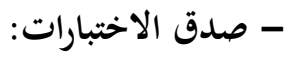

إِنَّ صدق الاختبارات هو: "أَنْ يقيس الاختبار ما وضع لقياسه، بمعنى أن الاختبار الصادق اختبار يقيس الوظيفة التي

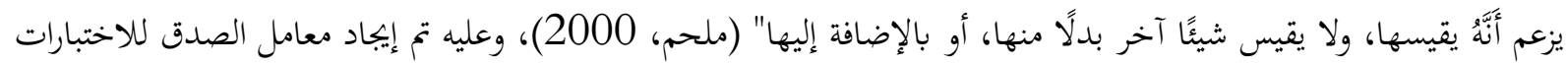

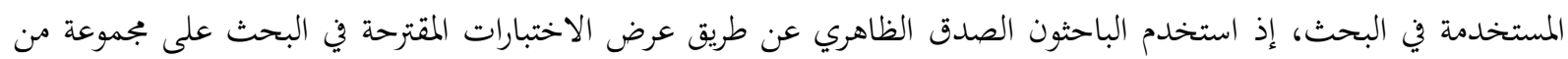

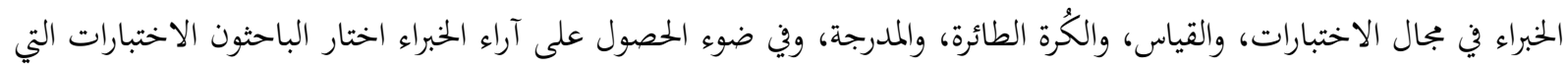

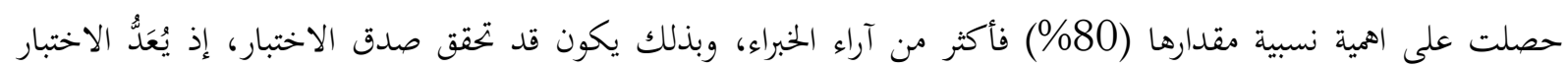

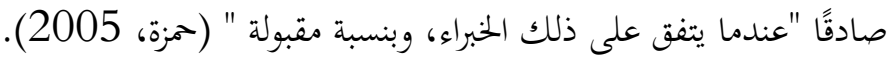

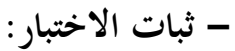

إِنَّ الاختبار الجيد هو الاختبار الذي يتصف بالثبات، فالاختبار الثابت هو: "الاختبار الذي يعطي نتائج متقاربة، أو

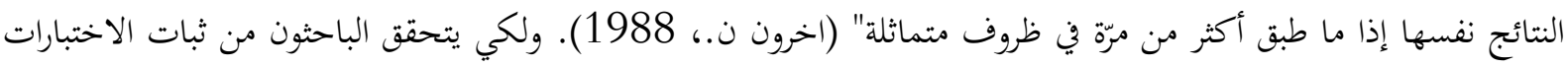


قاموا باستخدام طريقة الاختبار، وإعادة الاختبار على عينة مكونة من (10) طالبات من شعبتي (أ، ب)، وذلك في تمام الساعة

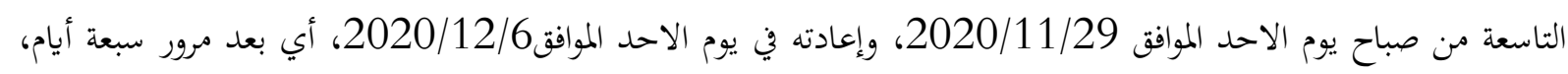
ويشير (ابراهيم، 2000) إلى أنَّهُ "لمعرفة ثبات الاختبار يعاد تطبيقه بعد مرور سبعة أيام على الاختبار الأول " (ابراهيم، 2000)، وبهدف معرفة الارتباط بين نتائج الاختبارين، قام الباحثون باستعمال قانون معامل الارتباط البسيط (بيرسون)، وتبيّن

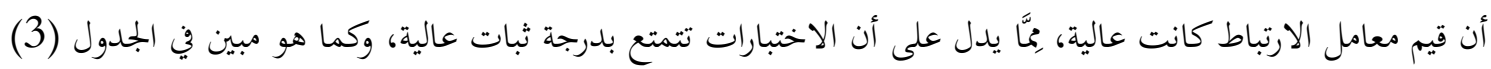

تعني موضوعية الاختبار: "الاتفاق في الآراء لأكثر من محكم لترتيب الأفراد وتقييمهم في أثناء الاختبار" (سلامة،

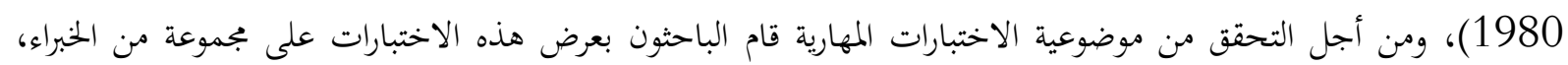

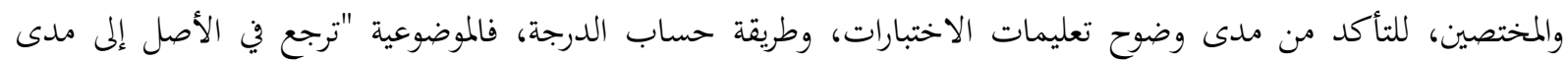

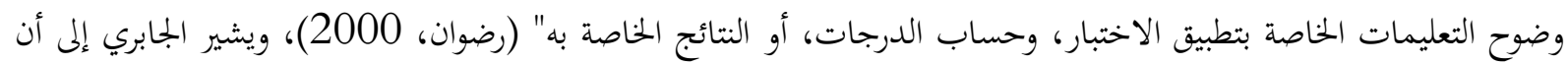

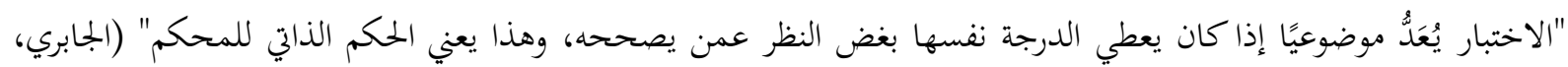

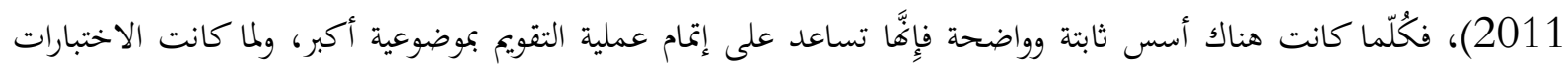

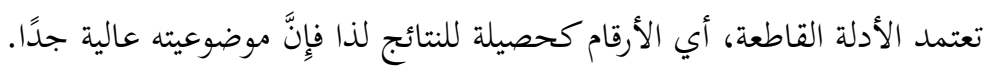
الجدول (3) يبيّن معاملات الثبات، والموضوعية للاختبارات قيد البحث

\begin{tabular}{|c|c|c|c|}
\hline الموضوعية & الثبات & 1 \\
\hline 0.89 & 0.86 & اختبار مهارة الإرسال المواجه من الأسفل. اختبار مهارة التمرير من الأعلى. & 2 \\
\hline 0.90 & 0.87 & اختبار التمرير من الأسفل. & 3 \\
\hline 0.90 & 0.88 & اختبار & \\
\hline
\end{tabular}

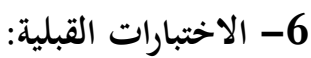

بعد تحديد الاختبارات المستعملة في البحث، وإيباد الأسس العلمية لها قام الباحثون بإعطاء وحدة تعريفية لأفراد العينة جميعها يوم الخميس الموافق 2020/12/10، لغرض تمكين الطالبات من معرفة شكل المهارة الأول ي، وكيفية تأديتها، بعدها

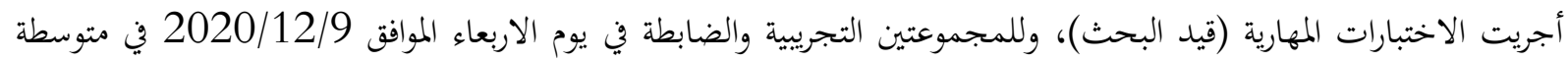

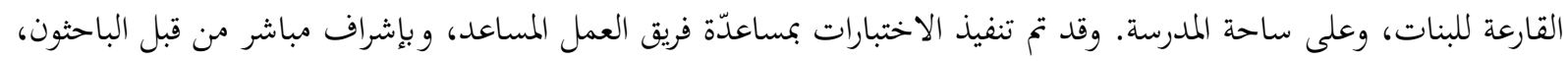

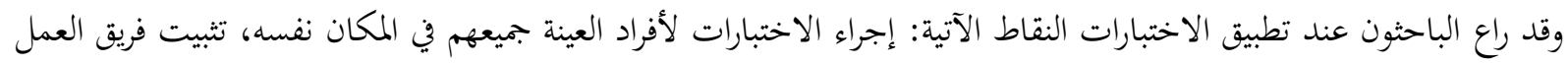

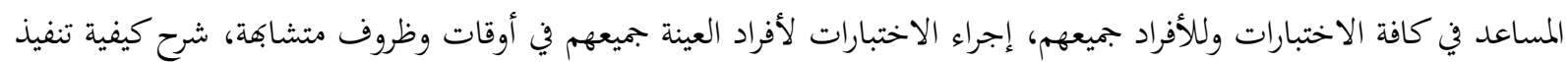

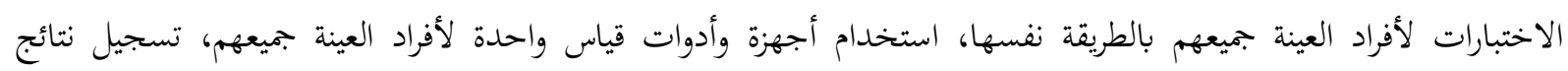

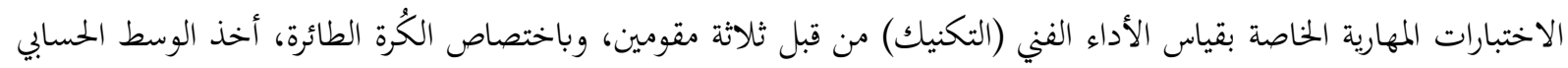
لدرجات ثلاثة مقومين لغرض تحديد الدرجة النهائية لكُلّ اختبار.

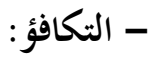

"لكي يستطيع الباحثون أن يرجع الفرق إلى العامل التجريبي يجب أن تكون المجموعات التجريبية متكافئة تمامًا في جميع ظروفها ما عدا المتغير التجريبي الذي يؤثر على المجموعة التجريبية" (بجيد، 1987)، ولغرض تحقيق ذلك قام الباحثون بإجراء 
عملية التكافؤ بين بجموعتي البحث في المتغيرات المستخدمة جميعها (قيد البحث)، وأظهرت النتائج عدم وجود فروق معنوية بين

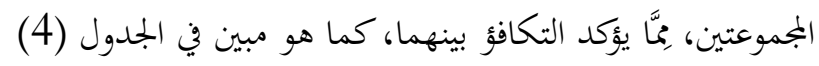
جدول (4) يبين التكافؤ بين مجموعتي البحث التجريبية والضابطة في اختبارات قيد البحث

\begin{tabular}{|c|c|c|c|c|c|c|c|c|c|}
\hline الدلالة & & قيمة t & \multicolumn{2}{|c|}{ المجمو عة الضابطة } & \multicolumn{2}{|c|}{ المجموعة التجرييية } & \multirow[b]{2}{*}{ القياس } & \multirow{2}{*}{ 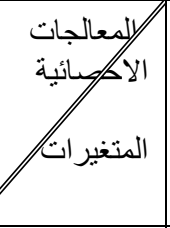 } & \\
\hline \multirow{4}{*}{ عند عندي } & مستو & المحسوبة & $\varepsilon$ & س & $\varepsilon$ & س & & & \\
\hline & $\begin{array}{r}0.8 \\
13\end{array}$ & 0.241 & 1.156 & 3.466 & 1.595 & 3.616 & درجة & الارسال الاسفل من & 1 \\
\hline & $\begin{array}{r}0.7 \\
83 \\
\end{array}$ & 0.279 & 0.794 & 2.416 & 1.300 & 2.281 & درجة & الاعلى من & 2 \\
\hline & $\begin{array}{r}0.9 \\
32\end{array}$ & 0.086 & 0.901 & 2.799 & 0.824 & 2.766 & درجة & الأسفليرمن & 3 \\
\hline
\end{tabular}

قيمة (t) الجدولية عند درجة حرية (18) وبمستوى دلالة (0.05) =0.10

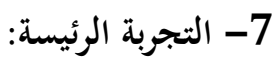

من أجل اتباع السياق العلمي السليم للتوصل إلى أدق النتائج لحل مشكلة البحث، ومن أجل تحقيق أهداف البحث

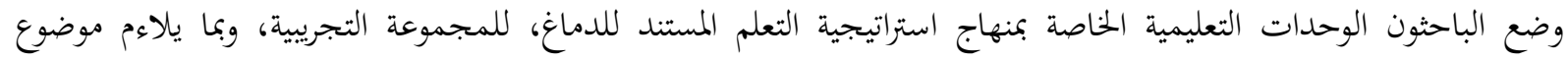
البحث وعينته، تضمنت (16) وحدة تعليمية، ولمدة (8) أسابيع، وبواقع وحدتين تعليميتين في الأسبوع ليومي السبت، والأحد،

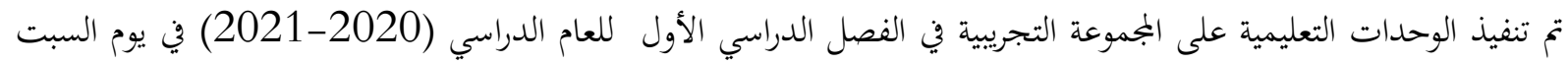
الموافق 2020/12/12، والانتهاء منها يوم السبت الموافق 2021/2/8 في ساحة متوسطة القارعة للبنات، تم استخدام (12)

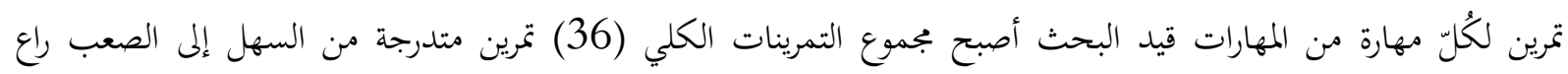

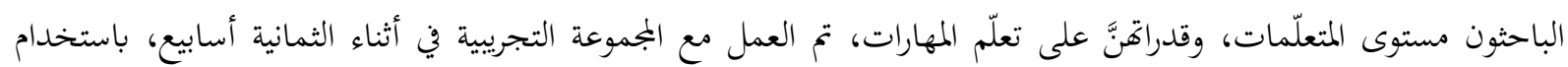

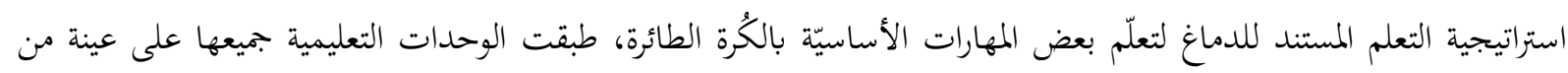
طالبات الصف الثاني متوسط/ متوسطة القارعة للبنات مراعية تسهيل عملية التعلّم إلى الطالبات باستخدام مبدأ التدرج في التعلّم من السهل إلى الصعب، ومن البسيط إلى المركب، إذ تم تطبيق التمرينات التي تتضمن التعلم المستند للدماغ بين الطالبات في فئنئ أثناء

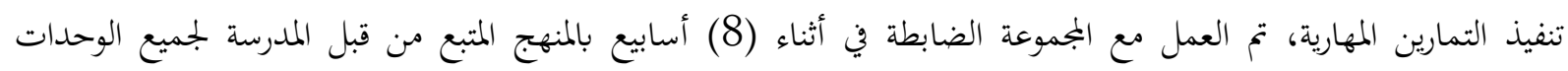

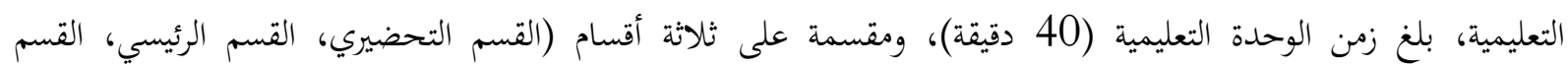

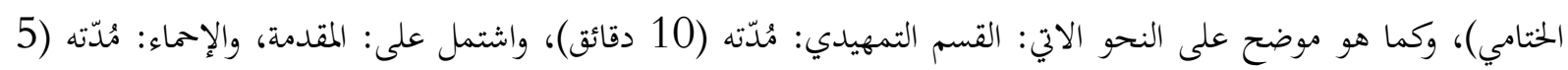

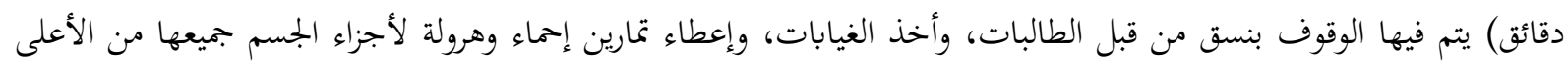

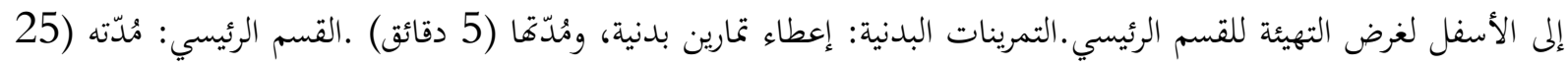

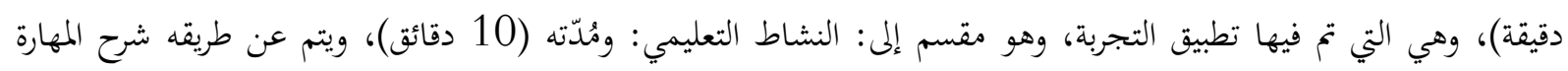

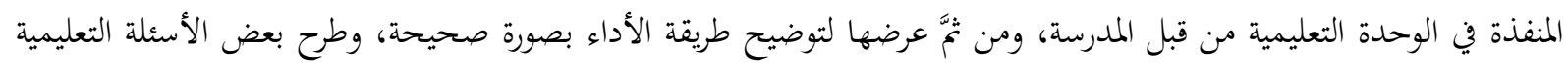

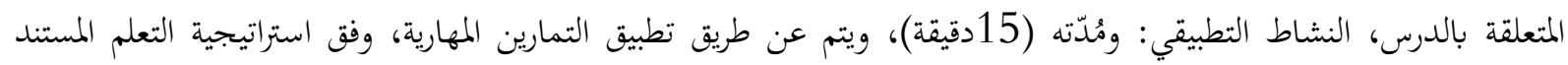
للدماغ، القسم الختامي: مُدّته (5 دقائق)، يتم في هذا القسم إعطاء لعبة صغيرة، لغرض تخفيف الجهاد للأعضاء، وبث الأثارة، 
والتشويق، والحماسة بين الطالبات، والوقوف بنسق، وإناء الوحدة التعليمية، والانصراف إلى الصف، وكما هو مبيّن في الجدول

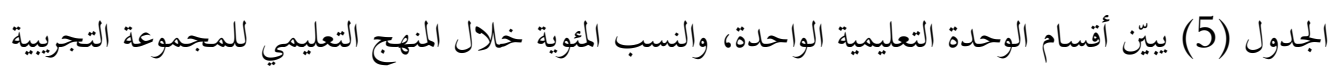

\begin{tabular}{|c|c|c|c|c|c|}
\hline \% النسبة المئوية & التطعيمي/ خلال المنهج & التعليمية/ دلال الوحدة & \multicolumn{2}{|c|}{ أقسام الوحدة التعليمية } & $ت$ \\
\hline$\% 40$ & (د160) & (د10) & الجانب التُعليمي (10د) & القسم & 1 \\
\hline$\% 60$ & 240 & $(د 15)$ & الجانب التطبيقي (15د) & $\begin{array}{r}\text { الرئيسي } \\
\text { (225) }\end{array}$ & \\
\hline$\% 100$ & 400 & $(-25)$ & & & 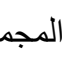 \\
\hline
\end{tabular}

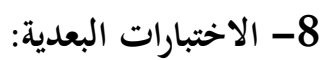

بعد الانتهاء من تنفيذ الوحدات التعليمية المعدّة على وفق استراتيجية التعلم المستند للدماغ، تم إجراء الاختبارات البعدية

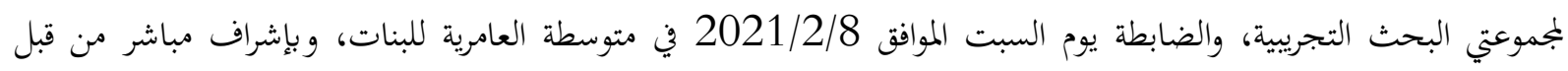

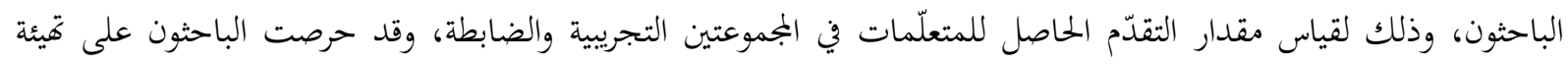

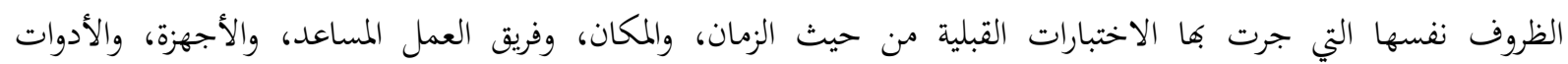
المستخدمة، وذلك لغرض الحصول على نتائج دقيقة.

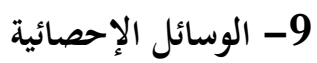

لغرض معالجة البيانات إحصائيًا استخدم الباحثون الحقيبة الإحصائية للعلوم الاجتماعية (SPSS)، وذلك لمعالجة البيانات الخناصة بالبحث.

3 - عرض النتائج وتحليلها ومناقشتها: 1- عرض وتحليل نتائج الاختبارات القبلية والبعدية للمجموعة التجريبة للمهارات الأساسية (قيد البحث) بالكرة الطائرة جدول (6) يبين قيمة T الخسوبة للمقارنة بين الاختبارات القبلية والبعدية للمجموعة التجريية للمهارات الأساسية (قيد البحث)

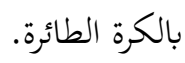

\begin{tabular}{|c|c|c|c|c|c|c|c|c|c|c|}
\hline \multirow{2}{*}{ الدلالة } & \multicolumn{2}{|r|}{ 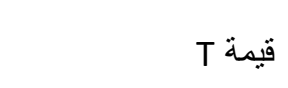 } & \multirow{2}{*}{ ف } & \multirow[b]{2}{*}{ نَ } & \multicolumn{2}{|c|}{ الاختبار البعدي } & \multicolumn{2}{|c|}{ الاختبار القبلي } & \multirow{2}{*}{ والقياسة } & \multirow{2}{*}{ 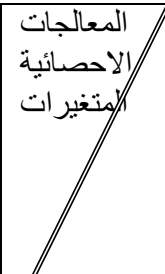 } \\
\hline & الخطبة & المحسوبة & & & $\varepsilon$ & سن & $\varepsilon$ & س س & & \\
\hline معنوي & 0.000 & 8.456 & 1.459 & 3.903 & 0.791 & 7.520 & 1.595 & 3.616 & درجة & الالمواجهال \\
\hline معنوي & 0.000 & 12.749 & 1.135 & 4.578 & 0.537 & 6.860 & 1.300 & 2.281 & درجة & من الإعلى \\
\hline معنوي & 0.000 & 10.460 & 1.089 & 3.603 & 0.598 & 6.370 & 0.824 & 2.766 & درجة & من الاسبفل \\
\hline
\end{tabular}

درجة الحرية (9) معنوي عند مستوى دلالة 20.05 
يتضح من الجدول (6) قيم الاوساط الحسابية والانخرافات المعيارية والوسط الحسابي للفروق وانحراف الفروق عن وسطها الحسابي وقيمة (T) المحسوبة ومستوى الدلالة في الاختبار القبلي والبعدي للمجموعة التجريبية للمهارات الأساسية بالكرة الطائرة (الارسال المواجه من الاسفل، التمرير من الاعلى، التمرير من الاسفل) . إذ تبين أن قيم الاوساط الحسابية لاختبار مهارة الارسال

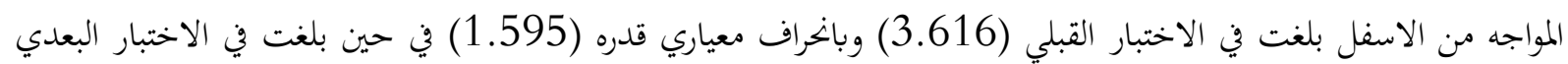

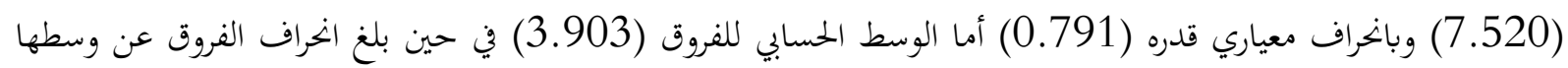

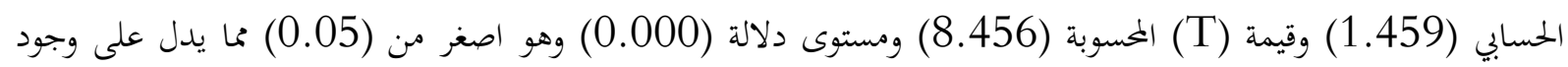
فروق معنوية في الاختبار القبلي والبعدي للمجموعة التجريبة. وتبين أن قيم الاوساط الحسابية لاختبار مهارة التمرير من الاعلى

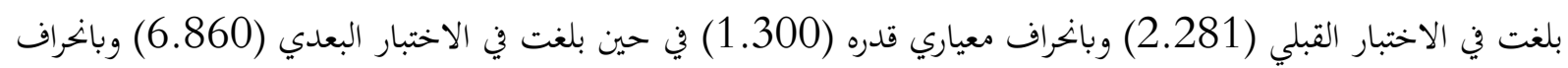

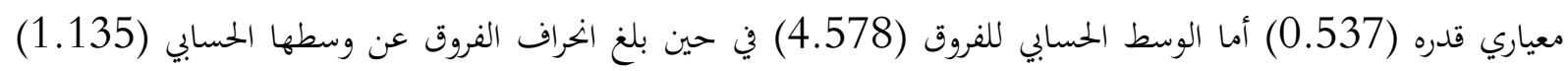

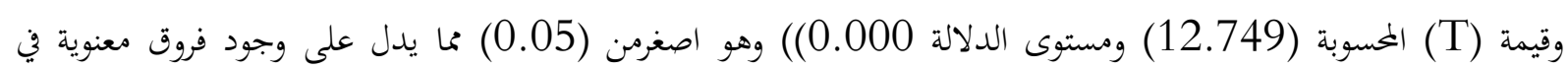

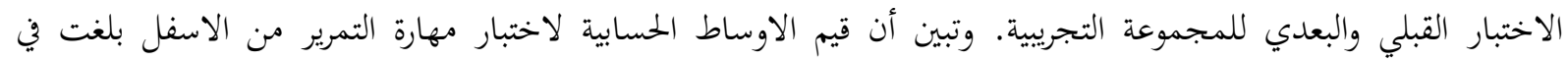

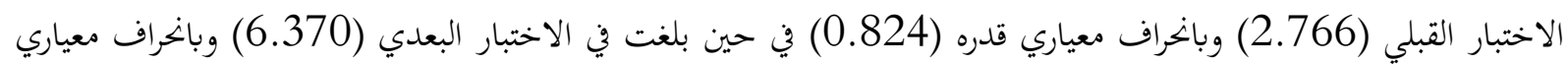

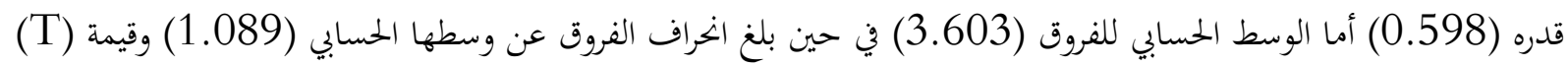
المحسوبة (10.460) ومستوى دلالة 0.000) وهو اصغرمن (0.05) مما يدل على وجود فروق معنوية في الاختبار القبلي

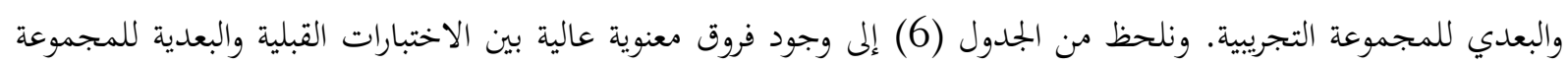

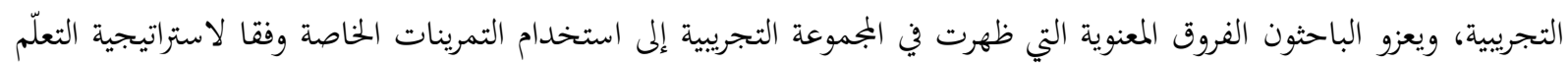

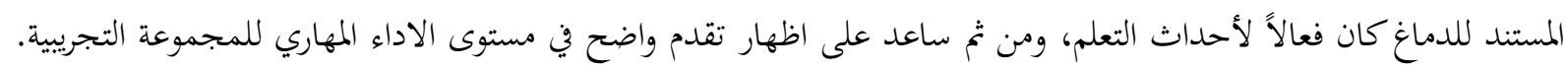

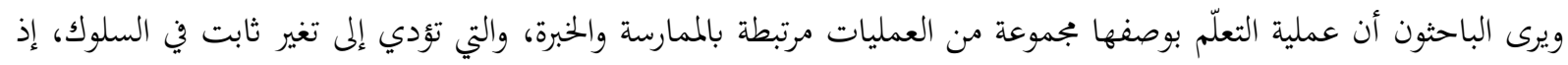

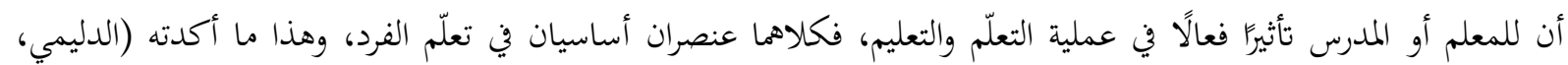

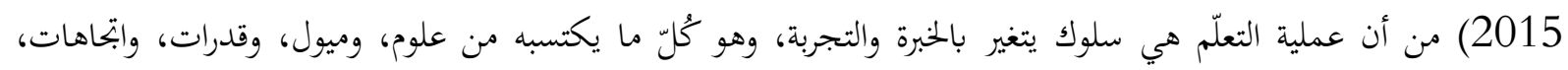

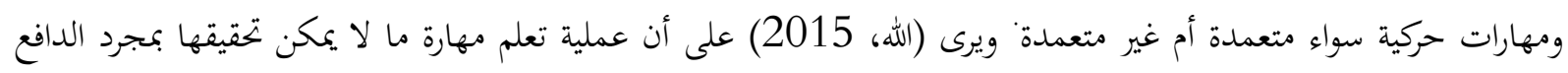

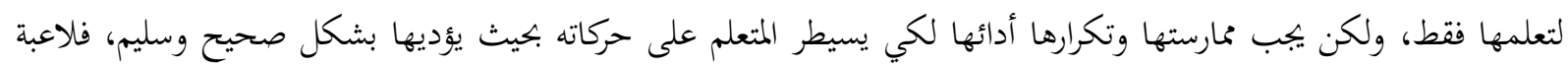
الكرة الطائرة لا تتعلم كيف تؤدي مهارة الارسال بمجرد أن تشاهد النموذج وانما تتعلم اللاعبة كل مهارات اللعبة بعد الشرح

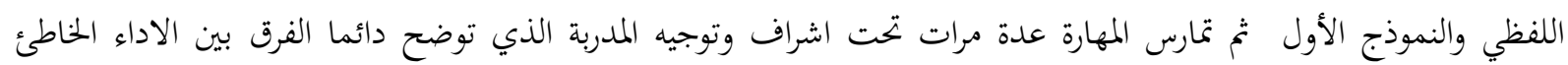

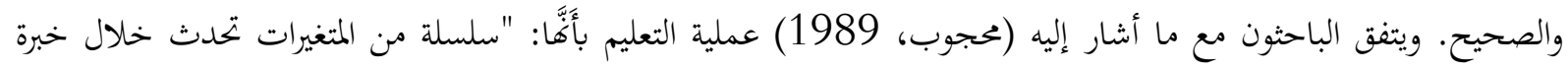

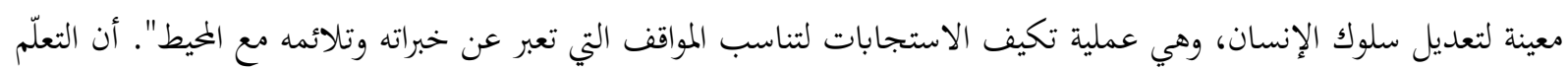
المستند للدماغ طريقة تعلّم وتعليم في أن واحدٍ يشترك فيها الطلبة بأنشطة متنوعة تسمح لهم بالإصغاء الإيجابي التي تبعل المتعلمين

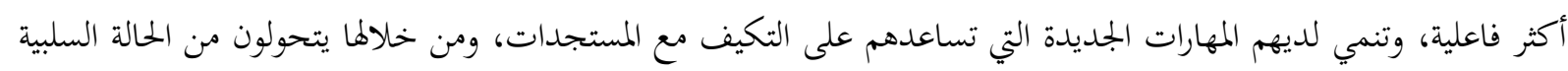

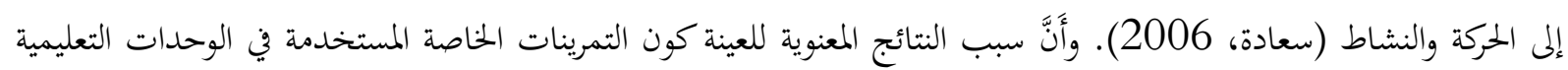

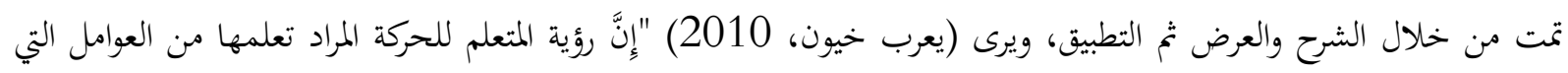

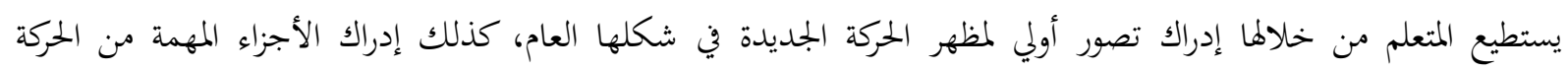

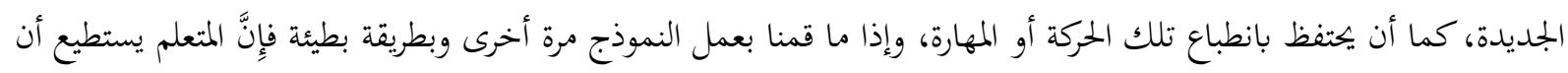

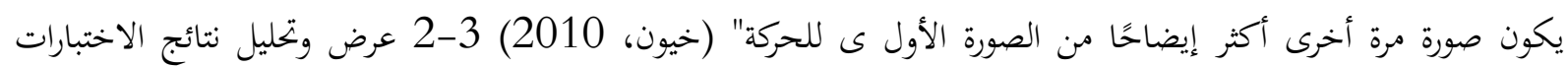
القبلية والبعدية للمجموعة الضابطة للمهارات الأساسية (قيد البحث) بالكرة الطائرة ومناقشتها البرها 


\begin{tabular}{|c|c|c|c|c|c|c|c|c|c|c|c|}
\hline \multirow{6}{*}{ 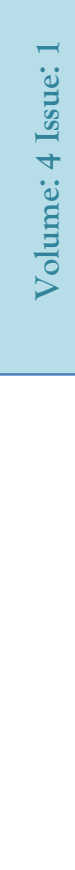 } & \multicolumn{11}{|c|}{ حدول (7) يبين قيمة T المحسوبة للمقارنة بين الاختبارات القبلية والبعدية للمجموعة الضابطة للمهارات الأساسية (قيد البحث) } \\
\hline & \multirow{2}{*}{ الدلالة } & \multicolumn{2}{|r|}{ قيمة T } & \multirow{2}{*}{$\underbrace{\varepsilon}$} & \multirow{2}{*}{ ن } & \multicolumn{2}{|c|}{ الاختبار البعدي } & \multicolumn{2}{|c|}{ الاختبار القبلي } & \multirow{2}{*}{ القباس } & \multirow{2}{*}{ |لالاحتصائية } \\
\hline & & 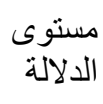 & المحسوبة & & & $\varepsilon$ & سَ & $\varepsilon$ & سَ & & \\
\hline & ي معنو & 0.007 & 3.512 & 1.264 & 1.403 & 0.689 & 4.870 & 1.156 & 3.466 & درجة & الارسال \\
\hline & مينو & 0.000 & 10.005 & 0.636 & 2.013 & 0.480 & 4.430 & 0.794 & 2.416 & درجة & التمرير من الاعلى \\
\hline & مي & 0.000 & 6.114 & 0.693 & 1.340 & 0.564 & 4.140 & 0.901 & 2.799 & درجة & التمفلير من \\
\hline
\end{tabular}

درجة الحرية (9) معنوي عند مستوى دلالة \05 0.05

يتضح من الجدول (7) قيم الاوساط الحسابية والانخرافات المعيارية والوسط الحسابي للفروق وانحراف الفروق عن وسطها الحسابي وقيمة (T) المحسوبة ومستوى الدلالة في الاختبار القبلي والبعدي للمجموعة الضابطة للمهارات الأساسية بالكرة الطائرة

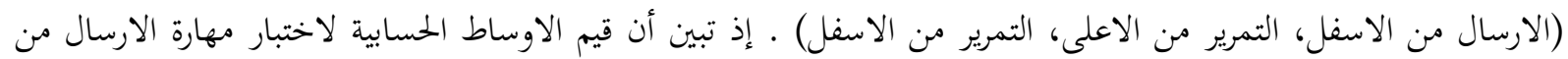
الاسفل بلغت في الاختبار القبلي (3.466) وبانحراف معياري قدره (156) (1.156) في حين بلغت في الاختبار البعدي (4.870) وبانحراف معياري قدره (0.689) أما الوسط الحسابي للفروق (1.403) في حين بلغ انحراف الفروق عن وسطها الحسابي

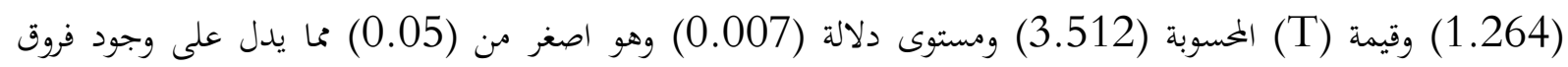

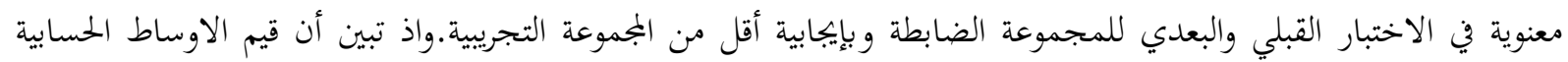

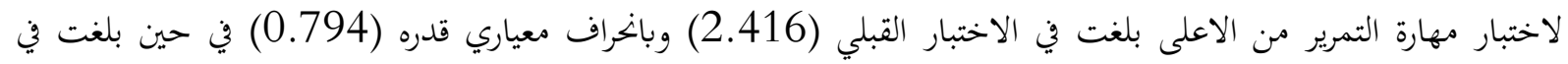

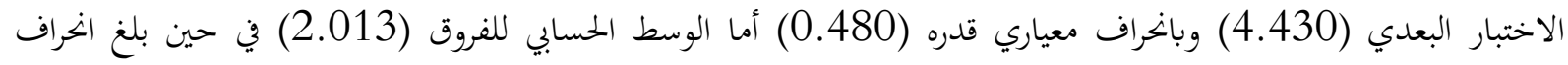
الفروق عن وسطها الحسابي (0.636) وقيمة (T) الخسوبة (10.005) ومستوى دلالة (0.000) وهو اصغر من (0.05)

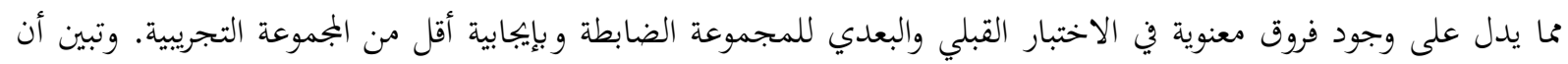

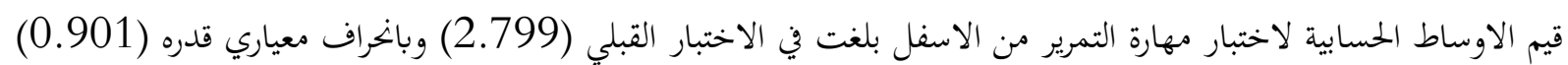

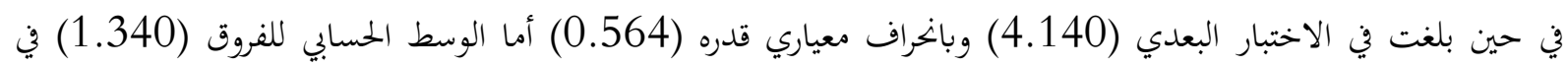

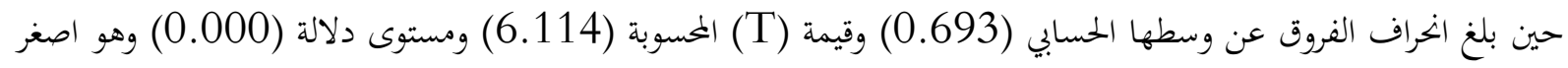
من (0.05) مما يدل على وجود فروق معنوية في الاختبار القبلي والبعدي للمجموعة الضابطة وبايجابية أقل من المجموعة

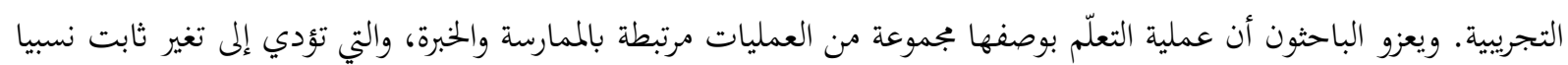

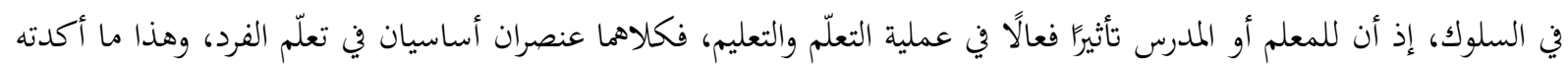

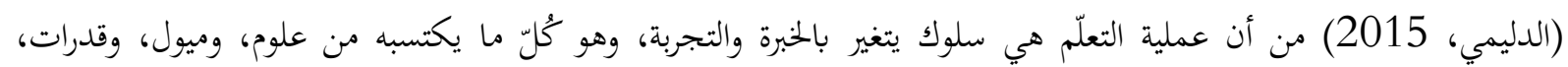

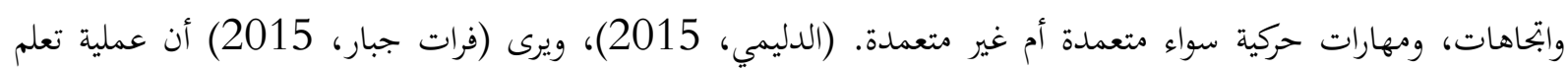

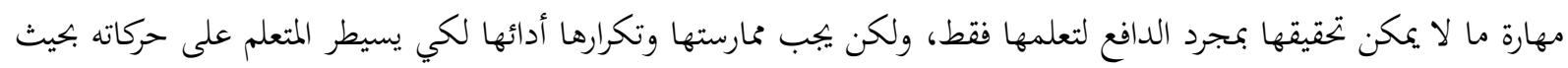
يؤديها بشكل صحيح وسليم (الله، 2015). وان اعتماد المجموعة الضابطة على أسلوب المدرس والى التكرارات المناسبة التي مئي 
رافقت الوحدات التعليمية بصورة مستمرة وكذلك التدرج في مستوى الصعوبات للمهارات والتي تضمن الأداء من الجميع إذ "إنّ الممارسة وبذل الجها بالتدريب والتكرارات المستمرة ضرورية في عملية التعلم والاكتساب كما أن التدريب عامل أساس في عملية

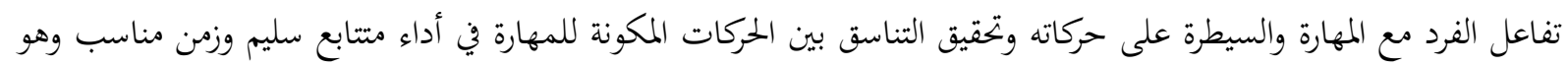
يزيد من تعلم وتطوير المهارة وإتقاها (صبحي، 2000).

2- عرض وتحليل نتائج الاختبارات البعدية للمجموعتين التجريبية والضابطة للمهارات الأساسية (قيد البحث) بالكرة الطائرة ومناقشتها جدول (8) يبين الاوساط الحسابية والانحرافات المعيارية وقيمة (T) المسوبة ومستوى الدلالة في الاختبارات البعدية للمجموعتين التجريية والضابطة للمهارات الأساسية (قيد البحث) بالكرة الطائرة.

\begin{tabular}{|c|c|c|c|c|c|c|c|c|c|}
\hline \multirow{3}{*}{ الدلالة } & \multicolumn{2}{|r|}{ قيمة t } & \multicolumn{2}{|c|}{ المجموعة الضابطة } & \multicolumn{2}{|c|}{ المجموعة التجريبية } & \multirow{3}{*}{ القياس } & \multicolumn{2}{|l|}{ /لالمعالجات الاحصائية } \\
\hline & الدلالة & المحسوبة & $\varepsilon$ & سَّ & $\varepsilon$ & سَّ & & & $ت$ \\
\hline & & & & & & & & المتغير ات & \\
\hline معنوي & 0.000 & 7.983 & 0.689 & 4.870 & 0.791 & 7.520 & درجة & الاسفل الارل المواجه من & 1 \\
\hline معنوي & 0.000 & 10.651 & 0.152 & 4.430 & 0.537 & 6.860 & درجة & التمرير من الاعلى & 2 \\
\hline معنوي & 0.000 & 8.576 & 0.564 & 4.140 & 0.598 & 6.370 & درجة & التمرير من الاسفل & 3 \\
\hline
\end{tabular}

درجة الحرية (18) معنوي عند مستوى دلالة 0.05

يتضح لنا من الجدول (8) قيم الاوساط الحسابية والانحرافات المعيارية وقيمة (T) المحسوبة ومستوى الدلالة في الاختبارات البعدية للمجموعتين التجريبة والضابطة للمهارات الأساسية بالكرة الطائرة (قيد البحث) ـ تبين أن قيمة الوسط الحسابي لمهارة

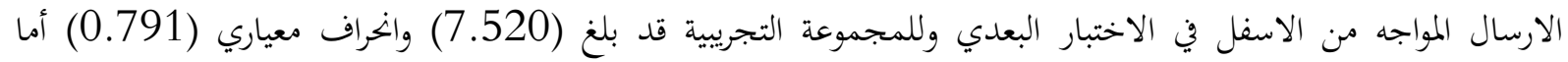

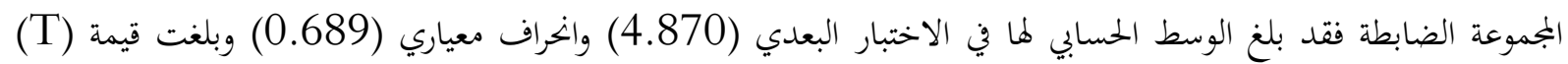
المحسوبة (7.983) ومستوى دلالة (0.000) وهو اصغر من (0.05) مما يدل على وجود فروق ذات دلالة احصائية في الاختبار البعدي للمجموعتين التجريبية والضابطة.اما قيمة الوسط الحسابي لمهارة التمرير من الاعلى في الاختبار البعدي

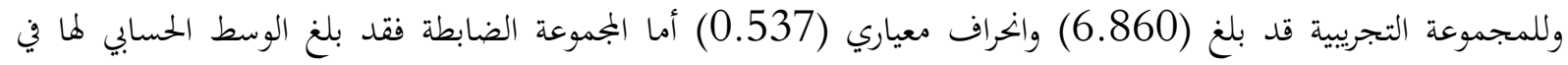
الاختبار البعدي (4.430) وانحراف معياري (0.152) وبلغت قيمة (T) المسوبة (10.651) ومستوى دلالة (0.000) وهو اصغر من (0.05) مما يدل على وجود فروق ذات دلالة احصائية في الاختبار البعدي للمجموعتين التجريبية والضابطة.

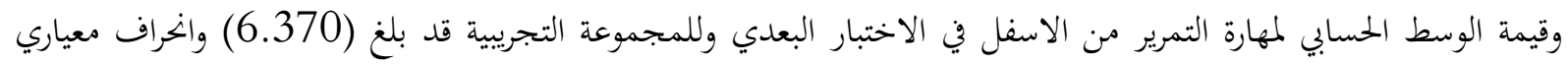

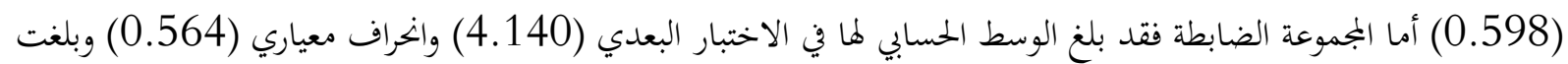

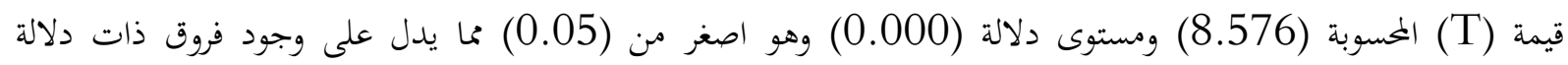

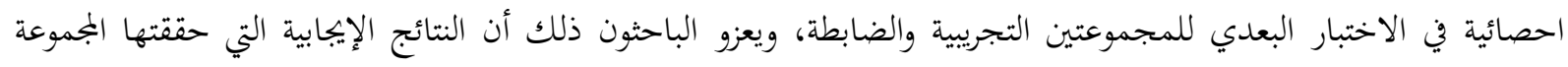

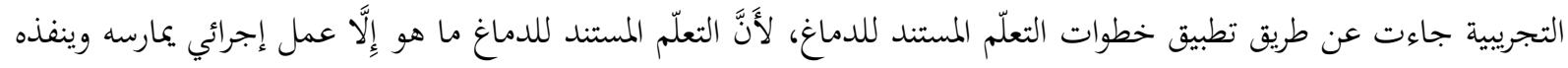
الطلبة داخل الصف الدراسي بمشاركة جميع المتعاملين، وييسر التعلّم بوساطة المعلم الميسر، ويختلف عن الإصغاء السلبي لما يقوله 
المتعلم، بحيث يشمل العمل والخبرات الإيجابية التي تساعدهم على فهم ما يسمعونه من معارف ومعلومات، وكتابة أهم الأفكار، وهذا ما تؤكده (البكري، 2016)من أنَّهَ يمكن تشبيه التعامل المستند للدماغ بالرياضة التي تكون للممارسة وليست للمشاهدة، ويرى الباحثون أَنَّهُ من خلال عرض النموذج تحقق لدى الطالبات عامل التشويق والأثارة، وميل الطالبات نخو الدّرس، وهذا أدى إلى الإسهام في التطوير الحاصل في المجموعة التجريبية، لأنَّهَّه من خلال عرض الأنموذج في الدّرس اقتربت المفاهيم المجردة إلى أذهان الطالبات، أن الهدف من هذه التمرينات الخاصة وفقا لاستراتيجية التعلم المستند للدماغ في تعلم بعض المهارات الأساسية وتحسينها بما يتلاءم مع قابليتهم وميولمم لغرض اكتساب التعلّم، والوصول إلى مستوى جيد لأداء المهارات الأساسيّة المراد تعلمها، فمن

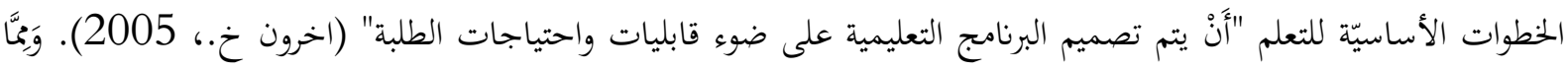
سبق نجد أهمية التمرينات الخاصة وفقا لاستراتيجية التعلم المستند للدماغ المستخدمة مع المجموعة التجريبية التي جاءت نتائجها مطابقة مع فرضيات البحث، إذ تطورت المجموعة التجريبية تطورًا معنويًا، وذلك من خلال نتائج الاختبارات، أما المجموعة الضابطة فقد تطورت هي أيضًا، ولكن ليس بالقدر الكافي، إذ تفوقت المجموعة التجريبية على المجموعة الضابطة في تعلم بعض المهارات الأساسية التي استخدمت استراتيجية التعلّم المستند للدماغ والتي تشير إلى الاداء الصحيح للمهارة بكافة تفصيلاكَا الدقيقة، وهذا ما سهّل أسلوب التعلمّ بنجاح الهدف وتحقيقه من الوصول بالعينة التجريبية تعلم بعض المهارات الأساسية بالكرة الطائرة للطالبات.

\section{خاتمة البحث:}

استناداً إلى ما أظهرته النتائج، وفي ضوء الاهداف والفرضيات توصل الباحثون إلى أن للتمرينات الخاصة وفقاً لاستراتيجية التعلم المستند للدماغ أثر واضح وفعال في تعلم بعض المهارات الأساسية لطالبات الصف الثاني متوسط بالكرة الطائرة. وان شرح وعرض وتطبيق المهارات في النشاط التعليمي والتطبيقي في الجزء الرئيسي من الوحدة التعليمية قد ساهم بشكل واضح في تعلمها. و ان زيادة خبرة الطالبات من خلال الممارسة والتكرار ساعدهن في تعلم المهارات الأساسية بالشكل الصحيح، وفي ضوء الحقائق العلمية التي اسفرت عنها نتائج البحث يوصي الباحثون ضرورة الاعتماد على استراتيجية التعلم المستند للدماغ في بناء المناهج التعليمية لطالبات الصف الثاني متوسط، ضرورة بناء مناهج تعليمية بالاعتماد على استراتيجية التعلم المستند للدماغ في تعلم بعض المهارات الدفاعية بالكرة الطائرة، وضرورة تطبيق التمرينات المهارية وفقا لاستراتيجية التعلم المستند للدماغ على عينات أخرى. 
المصادر:

ابراهيم احمد سلامة. (1980). الاختبارات و القياس ي التربية البدنية. القاهرة: مطبعة الجيزة.

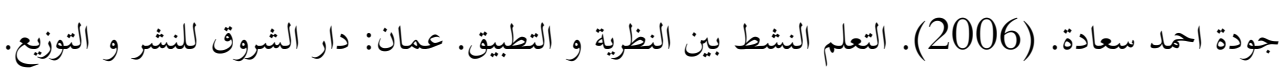
خليل ابراهيم و اخرون. (2005). أساسيات التدريس. عمان: دار المناهج.

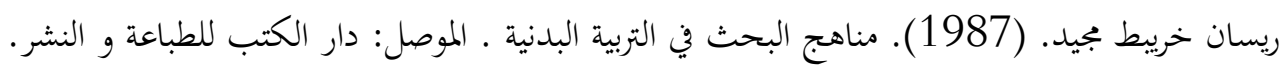
سامي ملحم. (2000). مناهج البحث في التربية وعلم النفس ـ عمان: دار الميسرة. سهام عبدالمنعم البكري. (2016). التعلم الحركي. عمان: دار الكتب و الوثائق. صباح حسين حمة. (2005). القياس و التقويم التربوي. صنعاء: مركز التربية للطباعة و النشر. عامر ابراهيم قندلجي. (2015). منهجية البحث العلمي. عمان: عامر ابراهيم -دار اليازوري العلمية . عبد الرزاق كاظم و اخرون. (2012). دليل مدرس التربية الرياضية للمرحلة المتوسطة. بغداد: مطبعة وزارة التربية. علي سلوم جواد. (2004). الاختبارات و القياس و الاحصاء في المجال الرياضي ـ القادسية: جامعة القادسية.

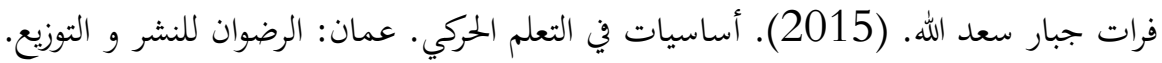

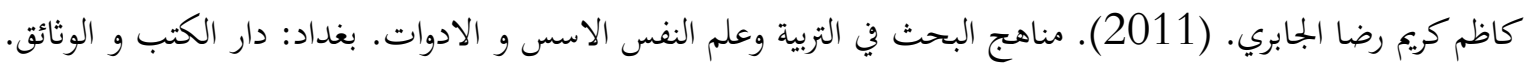

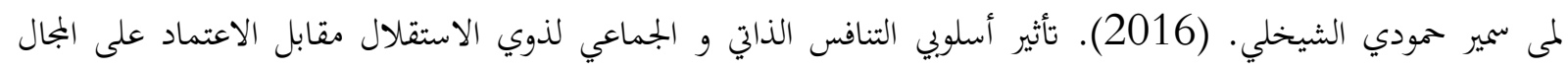

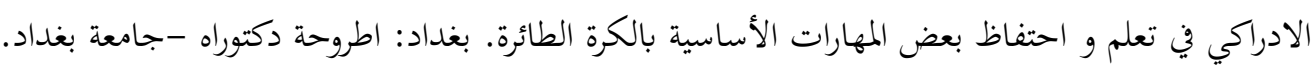

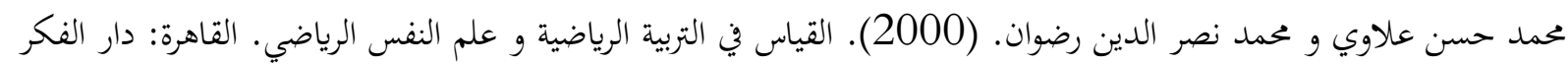

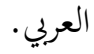

مروان عبدالمجيد ابراهيم. (2000). اسس البحث العلمي لاعداد الرسائل الجامعية ـ عمان: مؤسسة الوراق للنشر و التوزيع.

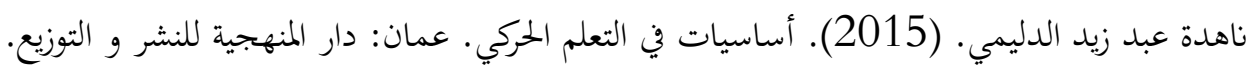

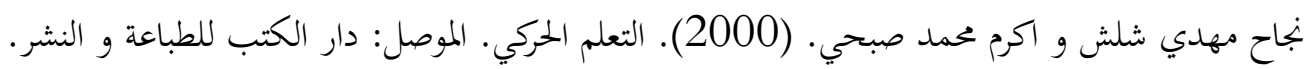

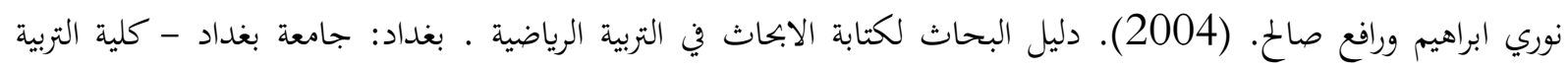
الرياضية

نوفل عبيدات و اخرون. (1988). البحث العلمي و مفهومة- ادواته -أساليبه. عمان: دار الفكر العربي.

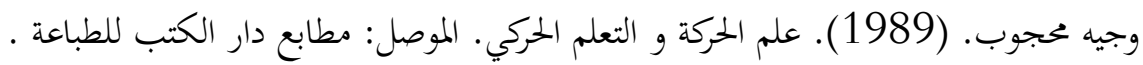
يعرب خيون. (2010). التعلم الحركي بين المبدأ و التطبيق. بغداد: دار الكتب و الوثيأق مطئق مطبعة الكلمة الطيبة. 